\title{
The Alvarez impact theory of mass extinction; limits to its applicability and the "great expectations syndrome"
}

\author{
Grzegorz Racki \\ Acta Palaeontologica Polonica 57 (4), 2012: 681-702 doi: http://dx.doi.org/10.4202/app.2011.0058
}

For the past three decades, the Alvarez impact theory of mass extinction, causally related to catastrophic meteorite impacts, has been recurrently applied to multiple extinction boundaries. However, these multidisciplinary research efforts across the globe have been largely unsuccessful to date, with one outstanding exception: the Cretaceous-Paleogene boundary. The unicausal impact scenario as a leading explanation, when applied to the complex fossil record, has resulted in force-fitting of data and interpretations ("great expectations syndrome"). The misunderstandings can be grouped at three successive levels of the testing process, and involve the unreflective application of the impact paradigm: (i) factual misidentification, i.e., an erroneous or indefinite recognition of the extraterrestrial record in sedimentological, physical and geochemical contexts, (ii) correlative misinterpretation of the adequately documented impact signals due to their incorrect dating, and (iii) causal overestimation when the proved impact characteristics are doubtful as a sufficient trigger of a contemporaneous global cosmic catastrophe. Examples of uncritical belief in the simple cause-effect scenario for the Frasnian-Famennian, Permian-Triassic, and Triassic-Jurassic (and the Eifelian-Givetian and Paleocene-Eocene as well) global events include mostly item-1 pitfalls (factual misidentification), with Ir enrichments and shocked minerals frequently misidentified. Therefore, these mass extinctions are still at the first test level, and only the F-F extinction is potentially seen in the context of item-2, the interpretative step, because of the possible causative link with the Siljan Ring crater (53 km in diameter). The erratically recognized cratering signature is often marked by large timing and size uncertainties, and item-3, the advanced causal inference, is in fact limited to clustered impacts that clearly predate major mass extinctions. The multi-impact lag-time pattern is particularly clear in the Late Triassic, when the largest $(100 \mathrm{~km}$ diameter) Manicouagan crater was possibly concurrent with the end-Carnian extinction (or with the late Norian tetrapod turnover on an alternative time scale). The relatively small crater sizes and cratonic (crystalline rock basement) setting of these two craters further suggest the strongly insufficient extraterrestrial trigger of worldwide environmental traumas. However, to discuss the kill potential of impact events in a more robust fashion, their location and timing, vulnerability factors, especially target geology and palaeogeography in the context of associated climate-active volatile fluxes, should to be rigorously assessed. The current lack of conclusive impact evidence synchronous with most mass extinctions may still be somewhat misleading due to the predicted large set of undiscovered craters, particularly in light of the obscured record of oceanic impact events. 
Key words: Bolide impacts, extraterrestrial markers, impact craters, mass extinctions, Cretaceous-Paleogene boundary, Triassic-Jurassic boundary, Frasnian-Famennian boundary.

Grzegorz Racki [grzegorz.racki@us.edu.pl], Department of Earth Sciences, Silesian University, Będzińska Str. 60, PL-41-200 Sosnowiec, Poland.

This is an open-access article distributed under the terms of the Creative Commons Attribution License (for details please see creativecommons.org), which permits unrestricted use, distribution, and reproduction in any medium, provided the original author and source are credited.

Farif Full text $(582.3 \mathrm{kB})$ 